\title{
Pengelolaan Operasional Homestay Di Desa Wisata Taro, Kecamatan Tegallalang, Kabupaten Gianyar-Bali
}

\author{
Ida Ayu Kalpikawati¹, Made Artajaya2, Ni Wayan Chintia Pinaria*3 \\ 1,2,3 Program Studi Bisnis Hospitaliti, Jurusan Hospitaliti, Politeknik Pariwisata Bali \\ Jl. Dharmawangsa, Kampial, Nusa Dua - 80363, Bali, Indonesia \\ 1idakalpika@yahoo.com, 2artajaya@ppb.ac.id, ${ }^{3 *}$ chintia_pinaria@yahoo.co.id \\ * Penulis Korespondesi
}

\begin{tabular}{l|l|l} 
Received: November, 2021 & Accepted: November, 2021 & Published: December, 2021
\end{tabular}

\begin{abstract}
Taro Tourism Village is one of the rapidly growing tourist villages in Bali. The Hospitality Business Study Program as one of the study programs at the Bali Tourism Polytechnic carries out community service activities in the Taro Tourism Village on March 20 to April 182021. The form of Community Service activities for the Hospitality Business Study Program in the Taro Tourism Village is assistance with the theme "Homestay Operational Management in Taro Tegallalang Village, Gianyar". This activity was attended by 11 participants who are homestay owners and managers in Taro Village, Pokdarwis members and the Taro Village community who want to develop their homes into homestays. Community Service Activities The Hospitality Business Study Program was carried out for 64 hours divided into 9 training sessions. Participants' assessment of the Community Service activities of the Hospitality Business Study Program was that most of the participants considered the material to be very relevant to their needs. All participants stated that after participating in all the activities, they felt that they had gained additional knowledge, insight, and skills in homestay operations.
\end{abstract}

Keywords: tourism village, mentoring, community service

\begin{abstract}
Abstrak
Desa Wisata Taro merupakan salah satu desa wisata yang sedang berkembang pesat di Bali. Program Studi Bisnis Hospitaliti sebagai salah satu program studi di Politeknik Pariwisata Bali melaksanakan kegiatan pengabdian kepada masyarakat di Desa Wisata Taro pada tanggal 20 Maret sampai dengan 18 April 2021. Bentuk kegiatan Pengabdian kepada Masyarakat Program Studi Bisnis Hospitaliti di Desa Wisata Taro adalah pendampingan dengan tema "Pengelolaan Operasional Homestay di Desa Taro Tegallalang Gianyar". Kegiatan ini diikuti oleh 11 peserta yang merupakan pemilik dan pengelola homestay di Desa Taro, anggota Pokdarwis serta masyarakat Desa Taro yang ingin mengembangkan rumahnya menjadi homestay. Kegiatan Pengabdian kepada Masyarakat Program Studi Bisnis Hospitaliti dilaksanakan selama 64 jam dibagi menjadi 9 kali pelatihan. Penilaian peserta terhadap kegiatan Pengabdian kepada Masyarakat Program Studi Bisnis Hospitaliti adalah sebagian besar peserta menilai materi sangat relevan dengan kebutuhan mereka.
\end{abstract}


Ida Ayu Kalpikawati, Made Artajaya, Ni Wayan Chintia Pinaria

Semua peserta menyatakan setelah mengikuti seluruh kegiatan merasa mendapatkan tambahan pengetahuan, wawasan, dan keterampilan dalam operasional homestay.

Kata kunci: desa wisata, pendampingan, pengabdian kepada masyarakat

\section{PENDAHULUAN}

Desa wisata saat ini menjadi program unggulan dari Kementerian Pariwisata dan Ekonomi Kreatif. Kementerian Pariwisata dan Ekonomi Kreatif menargetkan 244 desa wisata tersertifikasi menjadi desa wisata mandiri pada tahun 2024. Desa wisata merupakan wilayah pedesaan yang menawarkan suasana asli pedesaan, yang terdiri dari kehidupan masyarakat sehari-hari, keadaan ekonomi, sosial budaya, kebiasaan atau adat istiadat, tata ruang atau arsitektur bangunan yang khas, serta memiliki potensi untuk dikembangkan sebagai daya tarik pariwisata dengan dukungan atraksi, akomodasi, penyediaan makanan dan minuman serta kebutuhan wisata lainnya Hadiwijoyo (2012). Pengembangan desa wisata merupakan salah satu cara untuk meningkatkan kesejahteraan masyarakat di desa wisata tersebut.

Salah satu desa wisata yang saat sedang berkembang di Bali adalah Desa Wisata Taro. Desa Wisata Taro adalah desa tertua di Bali yang terletak di Kecamatan Tegallalang, Kabupaten Gianyar, Provinsi Bali. Pada tahun 2019 Desa Wisata Taro yang memperoleh penghargaan sebagai Desa Wisata Nusantara. Desa ini memiliki posona alam yang indah seperti persawahan, perkebunan dan hutan yang masih terjaga dengan baik. Selain pesona alam, adat istiadat dan budaya sangat dipertahankan oleh masyarakat setempat hingga saat ini. Dalam situs web Desa Taro yaitu taro.desa.id dinyatakan bahwa Desa Taro erat kaitannya dengan kedatangan Rsi Markandya. Made Puri, yang telah menjadi Bendesa Adat Taro sejak tahun 1952 menuturkan tentang kedatangan Rsi Markandya. Beliau berkata "Dari cerita tetua, konon desa ini ada berkat Rsi Markandya yang datang dari Jawa dan dalam tapanya melihat sinar dari kawasan ini," terangnya. Sinar inilah yang konon menyebabkan Rsi Markandya datang dan hendak tinggal di kawasan yang dulu disebut Sarwada. Sarwada merupakan singkatan dari Sarwa Ada (serba ada). Pada akhirnya desa ini berubah nama dan disebut Desa Taro.

Secara geografis Desa Taro merupakan bagian dari kawasan Munduk Gunung Lebah, dataran tinggi yang membujur dari Utara ke Selatan diapit oleh dua aliran sungai yakni sungai Oos Ulu Luh di sebelah Barat dan sungai Oos Ulu Muani di sebelah Timur. Kedua aliran sungai ini kemudian menyatu di tepi Barat Desa Ubud yang dikenal dengan nama Campuhan Ubud. Di bagian Utara Desa Taro berbatasan dengan Desa Apuan, Kintamani, di Timur dengan Desa Sebatu, Tegallalang, Selatan berbatasan dengan Desa Kelusa, Tegallalang, di Barat dengan Desa Puhu, Payangan. Wilayah Desa Taro terdiri dari 14 banjar yakni, Puakan, Pakuseba, Taro Kaja, Taro Kelod, Let, Sengkaduan, Pisang Kaja, Pisang Kelod, Patas, Belong, Ked, Alas Pujung, Alas Tatag, dan Alas Tebuana.

Desa Wisata Taro memiliki tiga potensi wisata yakni rural experience, culture and heritage dan natural landscapes. Terdapat sembilan daya tarik wisata yaitu Lembu Putih, D’Tunggir, Delodsema Village, Semara Ratih River, Alas Jaka, Pura Agung Gunung Raung, Tegal Dukuh Camp, Pemulan Bali Cooking School, dan Moringga Resources. Berdasarkan informasi yang diperoleh dari Ketua 
Ida Ayu Kalpikawati, Made Artajaya, Ni Wayan Chintia Pinaria

POKDARWIS Desa Taro Bapak Wayan Wardika bahwa potensi alam dan budaya yang dimiliki oleh Desa Wisata Taro belum didukung dengan keberadaan sarana akomodasi yang memadai untuk wisatawan menginap. Saat ini di Desa Taro terdapat tiga rumah masyarakat lokal yang sedang dikembangkan menjadi homestay namun belum beroperasi secara maksimal yakni Komang Petak, Jero Mangku House dan Made Bidel.

Ketua POKDARWIS dan Perbekel Desa Adat Taro sangat berharap Politeknik Pariwisata Bali melalui program studi Bisnis Hospitaliti dapat mendampingi pengelolaan tiga rumah tersebut dengan memberikan pelatihan-pelatihan sehingga rumah tersebut layak menjadi homestay yang dikelola secara profesional dan siap untuk dipasarkan kepada wisatawan. Ketua POKDARWIS dan Perbekel Desa Adat Taro juga memiliki harapan jika nanti tiga rumah ini berhasil dikembangkan menjadi homestay, dapat memotivasi rumah-rumah warga yang lain untuk menjadi homestay agar masyarakat secara langsung dapat menikmati dampak pengembangan pariwisata di Desa Taro. Program pengabdian kepada masyarakat program studi Bisnis Hospitaliti di Desa Taro ini merupakan program pengabdian lanjutan dari program pengabdian yang sebelumnya telah dilaksanakan pada tanggal 29-31 Oktober 2020 dengant tema Pemahaman Sikap Dasar Hospitaliti, Profesionalisme dan CHSE dalam rangka menunjang Usaha Kepariwisataan di Desa Taro, Kecamatan Tegallalang, Kabupaten Gianyar-Bali.

\section{METODE PELAKSANAAN KEGIATAN}

Kegiatan pengabdian kepada masyarakat yang dilaksanakan di Desa Taro Kecamatan Tegalalang Kabupaten Gianyar Bali bentuknya berupa pendampingan yang merupakan kelanjutan dari kegiatan pengabdian yang telah dilaksanakan oleh para Dosen Program Studi Bisnis Hospitaliti sebelumnya pada tahun 2020 yakni sifatnya sosialisasi yang tujuan awalnya hanya untuk menemukenali permasalahan yang dihadapi oleh pemilik dan pekerja Homestay yang berada di Desa Taro tersebut. Dari sosialisasi tersebut, ditemukanlah berbagai permasalahan yang dihadapi oleh para pemangku kepentingan yang ada di Desa Taro. Seiring berjalannya waktu munculah usulan dan gagasan yang disampaikan oleh para pemangku kepentingan di Desa Taro seperti Kepala Desa Taro, Pokdarwis Desa Taro, serta pemilik dan pekerja Homestay yang ada di Desa Taro yang langsung disampaikan oleh Kepala Desa Taro dan ketua Pokdarwis Desa Taro meminta kepada Koordinator Program Studi BHP untuk diadakan pendampingan dengan tujuan agar pemilik dan pekerja Homestay memiliki keterampilan yang memadai guna mendukung perkembangan pariwisata yang ada di Desa Taro. Bentuk pendampingan yang diminta tersebut yakni berupa pelatihan-pelatihan "Pengelolaan Operasional Homestay di Desa Taro, Kecamatan Tegallalang, Kabupaten Gianyar-Bali". Hal tersebut sejalan dengan pendapat Dessler, Gary, (2005) yang menyatakan bahwa pelatihan adalah proses mengajarkan karyawan baru yang ada sekarang, keterampilan dasar yang mereka butuhkan untuk menjalankan pekerjaan mereka.

Berdasarkan permintaan tersebut, maka ditetapkanlah 12 kompetensi luaran yang akan dimiliki berdasarkan hasil dari analisis kebutuhan yang telah dilakukan sebelumnya. Adapun 12 kompetensi luaran yang dimaksud adalah (1) Memahami industri pariwisata dan motivasi wisatawan, (2) Mengetahui jenis-jenis 
homestay dan layanan homestay, (3) Menangani permintaan dan pesanan pelanggan, (4) Menyiapkan kamar dan lingkungan homestay, (5) Memberikan pelayanan makanan dan minuman selama tamu tinggal di homestay, (6) Memproduksi makanan yang sehat aman dan bergizi, (7) Memberikan pelayanan yang berkualitas kepada pelanggan, (8) Mengaplikasikan prinsip dan praktik hygiene dan sanitasi, keselamatan kerja dan CHSE, (9) Memahami keknik untuk meningkatkan pendapatan homestay, (10) Mengaplikasikan pendekatan pemasaran berbiaya murah, (11) Membuat laporan keuangan homestay sederhana, (12) Berkomunikasi dalam bahasa inggris terkait operasional homestay.

Kegiatan pendampingan (pelatihan) tersebut dilaksanakan dengan menggunakan tiga metode pengajaran dan diakhiri dengan melakukan kunjungan serta diskusi langsung dengan pemilik dua Homestay yang ada di kawasan desa wisata Ubud. Metode pengajaran berupa kegiatan ceramah, diskusi dan praktek langsung yang dilakukan oleh para Dosen Program Studi Bisnis Hospitaliti dan melibatkan beberapa Dosen dari program studi lain yang ada lingkungan kampus Politeknik Pariwisata Bali dengan para peserta (masyarakat). Pelatihan diikuti oleh 11 peserta yang merupakan pemilik dan pengelola homestay di Desa Taro, anggota Pokdarwis serta masyarakat Desa Taro yang ingin mengembangkan rumahnya menjadi homestay.

\section{HASIL DAN PEMBAHASAN}

Kegiatan Pengabdian Kepada Masyarakat (PKM) Program Studi Bisnis Hospitaliti Politeknik Pariwisata Bali pada semester genap tahun 2021 dilaksanakan di Desa Taro Tegalalang Gianyar Bali mengambil tema "Pengelolaan Operasional Homestay di Desa Taro Tegalalang Gianyar". Kegiatan ini merupakan kegiatan lanjutan dari kegiatan sebelumnya yang telah dilaksanakan pada tanggal 29-30 Oktober 2020 dengan tema: Pemahaman Sikap dasar Hospitaliti, CHSE Dalam Rangka Menunjang Usaha Kepariwisataan Di Desa Taro Tegalalang Gianyar Bali".

Kegiatan PKM “Pengelolaan Operasional Homestay di Desa Taro Tegalalang Gianyar" dilaksanakan pada periode tanggal 20 Maret s.d 18 April 2021 dengan durasi 9x pelatihan dan total waktu 64 jam.

\subsection{Tahap Perencanaan}

1) Koordinasi dan analisis situasi dengan Kepala Desa Taro, Bapak I Wayan Warka dan Ketua Kelompok Sadar Wisata (POKDARWIS) Desa Taro, Bapak I Wayan Wardika, S.Tr.Par.

2) Melakukan penjajagan di lokus PKM yaitu di Desa Taro, Kabupaten Gianyar, pada tanggal 17-18 Desember 2020. Pada kegiatan penjajagan ini, Kepala Desa Taro dan Ketua POKDARWIS memberikan informasi tentang kebutuhan yang diperlukan oleh masyarakat Desa Taro, khususnya tentang pengelolaan homestay yang ada di Desa Wisata Taro. 


\subsection{Tahap Pelaksanaan}

Kegiatan PKM Program Studi Bisnis Hospitaliti telah dilaksanakan sesuai rencana awal dengan durasi kegiatan 9x pelatihan. Terdapat sedikit penyesuaian jadual disebabkan oleh kondisi yang terjadi di lapangan, namun secara keseluruhan kegiatan pengabdian dapat berjalan dengan baik dan lancar. Adapun pelaksanaan kegiatan PKM secara riil sebagai berikut:

Tabel 1: Jadual dan Materi Pelatihan Pengelolaan Operasional Homestay di Desa Taro Tegalalang Gianyar" Periode 20 Maret s.d 18 April 2021

\begin{tabular}{|c|c|c|c|}
\hline No & Hari/tanggal & Materi Pelatihan & Keterangan \\
\hline 1 & $\begin{array}{c}\text { Sabtu/ } \\
20 \text { Maret } 2021\end{array}$ & $\begin{array}{l}\text { Pariwisata dan Homestay ( } 2 \text { jam }) \\
\text { Bahasa Inggris ( } 2 \text { jam) } \\
\text { Penanganan Reservasi ( } 2 \text { jam })\end{array}$ & $\begin{array}{l}\text { Venue: } \\
\text { Fire Flies Garden }\end{array}$ \\
\hline 2 & $\begin{array}{c}\text { Sabtu/ } \\
27 \text { Maret } 2021\end{array}$ & $\begin{array}{l}\text { Penaganan Reservasi ( } 2 \text { jam) } \\
\text { Bahasa Inggris (2 jam) } \\
\text { Pemasaran dan Promosi Homestay ( } 2 \\
\text { jam) } \\
\text { Pelayanan kepada Pelanggan ( } 2 \text { jam) }\end{array}$ & $\begin{array}{c}\text { Venue: } \\
\text { Fire Flies Garden }\end{array}$ \\
\hline 3 & $\begin{array}{c}\text { Kamis/ } \\
1 \text { April } 2021\end{array}$ & $\begin{array}{l}\text { Bahasa Inggris (2jam) } \\
\text { Pemasaran dan Promosi Homestay } \\
(2 \text { jam) } \\
\text { Pelayanan Kepada Pelanggan (Praktik: } \\
4 \text { jam) }\end{array}$ & $\begin{array}{c}\text { Venue: } \\
\text { Tegal Dukuh Camp }\end{array}$ \\
\hline 4 & $\begin{array}{c}\text { Senin/ } \\
5 \text { April } 2021\end{array}$ & $\begin{array}{l}\text { Catatan dan laporan Keuangan } \\
\text { Homestay (Teori dan Praktik : 6jam) }\end{array}$ & $\begin{array}{c}\text { Venue: } \\
\text { Moringga Holiday }\end{array}$ \\
\hline 5 & $\begin{array}{l}\text { Jumat/ } 9 \text { April } \\
2021\end{array}$ & $\begin{array}{l}\text { Hygiene dan Sanitasi ( } 2 \text { jam) } \\
\text { Meningkatkan Penjualan Homestay ( } 4 \\
\text { jam) } \\
\text { Perencanaan Menu ( } 2 \text { jam) }\end{array}$ & $\begin{array}{l}\text { Venue : } \\
\text { Venus One Tourism } \\
\text { Academi (VOTA) }\end{array}$ \\
\hline 6 & $\begin{array}{c}\text { Sabtu/ } \\
10 \text { April } 2021\end{array}$ & $\begin{array}{l}\text { Praktik Memproduksi Makanan } \\
\text { (Praktik: } 8 \text { jam) }\end{array}$ & $\begin{array}{c}\text { Venue: } \\
\text { Venus One Tourism } \\
\text { Academy (VOTA) }\end{array}$ \\
\hline 7 & $\begin{array}{c}\text { Jumat/16 April } \\
2021\end{array}$ & $\begin{array}{l}\text { Pelayanan Makanan dan Minuman } \\
\text { (Teori dan Praktik: } 6 \text { jam) }\end{array}$ & $\begin{array}{c}\text { Venue : } \\
\text { Semara Ratih River }\end{array}$ \\
\hline 8 & $\begin{array}{c}\text { Sabtu/ } \\
17 \text { April } 2021\end{array}$ & $\begin{array}{l}\text { Penerapan CHSE di Homestay (2jam) } \\
\text { Pelayanan Housekeeping (Teori dan } \\
\text { Praktik: 6jam) }\end{array}$ & $\begin{array}{c}\text { Venue: } \\
\text { Bali Coconut House }\end{array}$ \\
\hline 9 & $\begin{array}{c}\text { Minggu/ } \\
18 \text { April } 2021\end{array}$ & $\begin{array}{l}\text { Praktik Kerja Lapangan berupa Kegiatan } \\
\text { Studi Tiru di: Nick's Homestay dan } \\
\text { Gunung Merta Bungalow Ubud (6jam) }\end{array}$ & $\begin{array}{l}\text { Venue : UHSA } \\
\text { (Ubud Homestay } \\
\text { Association) }\end{array}$ \\
\hline
\end{tabular}

Sumber: Program Studi Bisnis Hospitaliti, 2021

Pada Tabel 1 di atas adalah materi dan jadual pelatihan "Pengelolaan Operasional Homestay di Desa Taro Tegalalang Gianyar". Terdapat 14 materi dengan total waktu 64 jam pelatihan yang diberikan kepada peserta, meliputi : Pariwisata dan Homestay, Bahasa Inggris, Hygiene dan Sanitasi, Penanganan Reservasi, Pelayanan Kepada Pelanggan, Meningkatkan Penjualan Homestay, Catatan dan Laporan keuangan, Pemasaran dan Promosi Homestay, Pelayanan Tata Graha (Housekeeping), Penerapan CHSE di Homestay, Pelayanan Makanan dan Minuman, Perencanaan Menu, Praktik Memproduksi Makanan. Penyajian materi selama pelatihan diberikan oleh Narasumber yang merupakan Dosen Program Studi Bisnis Hospitaliti bekerjasama dengan Dosen Manajemen Tata 
Ida Ayu Kalpikawati, Made Artajaya, Ni Wayan Chintia Pinaria

Boga, Manajemen Tata Hidangan dan Manajemen Divisi Kamar. Materi yang disajikan sesuai dengan kompetensi masing-masing narasumber

Sebagai akhir dari materi pelatihan peserta mendapat kesempatan untuk melaksanakan kegiatan Praktik Kerja Lapangan berupa kegiatan Studi Tiru dengan mengunjungi dan melihat secara langsung operasional homestay yang riil. Studi Tiru dilaksanakan di destinasi wisata Ubud terselenggara atas kerjasama Program Studi Bisnis Hospitaliti dengan Ubud Homestay Association (UHSA). Peserta pelatihan akhirnya mendapat pengalaman langsung melihat Operasional homestay di Nick's Homestay dan Gunung Merta Bungalow Ubud yang merupakan anggota dari UHSA.

Untuk mengetahui efektifitas pelaksanaan program Pengabdian Kepada Masyarakat Program Studi Bisnis Hospitaliti maka dilakukan evaluasi. Evaluasi dilakukan dengan meminta umpan balik dari para peserta pelatihan melalui angket atau kuesioner. Umpan balik dari peserta dibagi dalam 2 kategori yaitu umpan balik terkait materi pelatihan dan umpan balik terkait pelaksanaan pelatihan secara umum yang ditampilkan dalam Tabel 2 dan Tabel 3 berikut:

Tabel 2: Evaluasi Peserta Pelatihan PKM Terhadap Materi Pelatihan

"Pengelolaan Operasional Homestay di Desa Taro Tegalalang Gianyar"

\begin{tabular}{|c|c|c|c|c|c|}
\hline & & \multicolumn{3}{|c|}{ Penilaian } & Jumlah \\
\hline No & Materi Pelatihan & $\begin{array}{l}\text { Kurang } \\
\text { Relevan }\end{array}$ & Relevan & $\begin{array}{c}\text { Sangat } \\
\text { Relevan }\end{array}$ & $\begin{array}{c}\text { Responden } \\
\text { (orang) }\end{array}$ \\
\hline 1 & Pariwisata dan Homestay & 0 & 1 & 10 & 11 \\
\hline 2 & Bahasa Inggris & 0 & 0 & 11 & 11 \\
\hline 3 & Penanganan Reservasi & 0 & 1 & 10 & 11 \\
\hline 4 & Pemasaran dan Promosi Homestay & 0 & 2 & 9 & 11 \\
\hline 5 & Pelayanan kepada Pelanggan & 0 & 2 & 9 & 11 \\
\hline 6 & Perencanaan Menu & 0 & 2 & 9 & 11 \\
\hline 7 & Praktik Memproduksi Makanan & 0 & 1 & 10 & 11 \\
\hline 8 & Hygiene \& Sanitasi Operasional Homestay & 0 & 2 & 9 & 11 \\
\hline 9 & Penerapan CHSE di Homestay & 0 & 2 & 9 & 11 \\
\hline 10 & Meningkatkan Penjualan Homestay & 0 & 3 & 8 & 11 \\
\hline 12 & $\begin{array}{l}\text { Pelayanan Makanan \& Minuman (Teori + } \\
\text { Praktik) }\end{array}$ & 0 & 1 & 10 & 11 \\
\hline 13 & Pelayanan Tata Graha (Teori + Praktik) & 0 & 1 & 10 & 11 \\
\hline 14 & Catatan \& Laporan Keuangan Homestay & 0 & 2 & 9 & 11 \\
\hline 15 & $\begin{array}{l}\text { Studi Tiru (Praktik Kerja Lapangan) } \\
\text { Pengelolaan Homestay }\end{array}$ & 0 & 0 & 11 & 11 \\
\hline
\end{tabular}

Sumber: kuesioner pelatihan, 2021

Peserta pelatihan memberikan penilaian yang sangat baik terhadap materi pelatihan yang didiskusikan selama kegiatan pelatihan. Sebagian besar peserta meyatakan mahwa materi pelatihan yang diberikan sangat relevan dengan kebutuhan yang mereka miliki. Materi pelatihan dinyatakan sangat relevan untuk peningkatan kompetensi dalam mengelola operasional homestay di Desa Taro.

Semua peserta menyatakan setelah mengikuti pelatihan merasa mendapatkan tambahan pengetahuan, wawasan, dan keterampilan. Kegiatan pelatihan dinyatakan sangat positif, penyajian dari narasumber yang baik sehingga 
Ida Ayu Kalpikawati, Made Artajaya, Ni Wayan Chintia Pinaria

mudah untuk dipahami dan diimplementasikan. Peserta juga berpendapat bahwa pelatihan menjadi penting untuk dilaksanakan di masa yang akan datang.

Umpan balik kedua adalah pendapat peserta pelatihan terkait pelaksanaan pelatihan yang terklasifikasi dalam; pernyataan kepuasan secara umum terhadap kegiatan pelatihan, pelaksanaan teknis kegiatan, materi pelatihan, saran bagi pelatihan di masa depan, dan rencana peserta setelah pelatihan. Adapun paparan dari evaluasi yang diberikan peserta adalah seperti ditampilkan pada Tabel 3 di bawah.

Hasil tabulasi koesioner dioleh menggunakan rumus Sugiyono (2013) sebagai berikut:

Nilai tertinggi : 5

Nilai terendah : 1

Range $\quad$ : 5-1 $=4$

Panjang interval dihitung dengan rumus:

$\mathrm{C}=\frac{\mathrm{R}}{\mathrm{K}}+\frac{4}{5}=0,8$

Keterangan:

$\mathrm{C}=$ Interval Kelas

$\mathrm{R}=$ Range

$\mathrm{K}=$ Jumlah Klasifikasi

Kriteria Jawaban Responden:

1. Sangat baik : 4,20-5,00

2. Baik : $3,40-4,19$

3. Cukup baik : 2,60-3,39

4. Kurang baik : $1,80-2,59$

5. Tidak baik : 0,00-1,79

Tabel 3 di bawah ini adalah hasil evaluasi peserta pelatihan terhadap pelaksanaan kegiatan PKM Program Studi Bisnis Hospitaliti di Desa Taro. Nilai rata-rata yang diperoleh kemudian dimasukkan dalam kriteria sesuai jawaban responden.

Tabel 3: Evaluasi Peserta Pelatihan PKM terkait Pelaksanaan kegiatan

"Pengelolaan Operasional Homestay di Desa Taro Tegalalang Gianyar"

\begin{tabular}{clcc}
\hline No & \multicolumn{1}{c}{ Pernyataan } & $\begin{array}{c}\text { Nilai rata- } \\
\text { rata }\end{array}$ & Kriteria \\
\hline $\mathbf{1}$ & $\begin{array}{l}\text { Secara umum seberapa puas anda dalam mengikuti kegiatan } \\
\text { pelatihan ini? }\end{array}$ & 4,92 & Sangat Baik \\
\hline $\mathbf{2}$ & $\begin{array}{l}\text { Seberapa cocok dan membantu materi pelatihan ini terhadap } \\
\text { kebutuhan anda? }\end{array}$ & 4,92 & Sangat Baik \\
\hline $\mathbf{3}$ & $\begin{array}{l}\text { Seberapa tingkat kepuasan anda terhadap masing-masing } \\
\text { komponen sebagai berikut: (Acara Pembukaan) }\end{array}$ & 4,67 & Sangat Baik \\
\hline $\mathbf{4}$ & $\begin{array}{l}\text { Seberapa tingkat kepuasan anda terhadap masing-masing } \\
\text { komponen sebagai berikut: (Seminar kit) }\end{array}$ & 4,58 & Sangat Baik \\
\hline $\mathbf{5}$ & $\begin{array}{l}\text { Seberapa tingkat kepuasan anda terhadap masing-masing } \\
\text { komponen sebagai berikut: (Koordinasi/ komunikasi) }\end{array}$ & 4,75 & Sangat Baik \\
\hline $\mathbf{6}$ & $\begin{array}{l}\text { Seberapa tingkat kepuasan anda terhadap masing-masing } \\
\text { komponen sebagai berikut: (Transportasi) }\end{array}$ & 4,58 & Sangat Baik \\
\hline $\mathbf{7}$ & $\begin{array}{l}\text { Seberapa tingkat kepuasan anda terhadap masing-masing } \\
\text { komponen sebagai berikut: (Studi Tiru Homestay Ubud) }\end{array}$ & 4,75 & Sangat Baik \\
\hline
\end{tabular}




\begin{tabular}{clcc}
\hline $\mathbf{8}$ & $\begin{array}{l}\text { Seberapa tingkat kepuasan anda terhadap masing-masing } \\
\text { komponen sebagai berikut: (Venue/tempat pelatihan) }\end{array}$ & 4,58 & Sangat Baik \\
\hline $\mathbf{9}$ & $\begin{array}{l}\text { Seberapa tingkat kepuasan anda terhadap masing-masing } \\
\text { komponen sebagai berikut: (Kegiatan Praktik) }\end{array}$ & 4,67 & Sangat Baik \\
\hline $\mathbf{1 0}$ & $\begin{array}{l}\text { Seberapa tingkat kepuasan anda terhadap masing-masing } \\
\text { komponen sebagai berikut: (Acara Penutupan) }\end{array}$ & 4,58 & Sangat Baik \\
\hline $\mathbf{1 1}$ & $\begin{array}{l}\text { Seberapa tingkat kepuasan anda terhadap masing-masing } \\
\text { komponen sebagai berikut: (Snack \& Makan Siang) }\end{array}$ & 4,58 & Sangat Baik \\
\hline & & 4,69 & Sangat Baik \\
\hline
\end{tabular}

Sumber: kuesioner pelatihan, 2021

Berdasarkan Tabel 3 di atas nilai rata-rata yang diberikan peserta terhadap pelaksanaan pelatihan secara umum adalah 4,69 dengan kriteria sangat baik. Peserta menilai secara teknis sangat puas terhadap pelaksanaan pelatihan dan seluruh rangkaian kegiatan mulai dari acara pembukaan, koordinasi dan komunikasi, kegiatan praktik, tempat pelatihan, transportasi, kegiatan studi tiru di destinasi wisata Ubud, penutupan kegiatan, kudapan (snack) dan makan siang. Peserta juga memberi komentar menyampaikan harapan agar pelatihan sejenis ini dapat dilakukan di masa yang akan datang. Pelatihan yang diharapkan dapat dilakukan dimasa depan adalah peningkatan kompetensi di bidang entrepreneurship, service excellent dan peningkatan kompetensi bidang kepemanduan wisata (guiding technique).

\section{KESIMPULAN}

Kegiatan Pengabdian Kepada Masyarakat Program Studi Bisnis Hospitaliti semester genap tahun 2021 dilaksanakan di Desa Taro Tegalalang Gianyar Bali mengambil tema "Pengelolaan Operasional Homestay di Desa Taro Tegalalang Gianyar". Bentuk kegiatan berupa pelatihan dengan total waktu 64 jam yang diberikan dalam durasi 9x pelatihan. Kegiatan PKM di Desa Taro bertujuan agar para peserta PKM memiliki kompetensi (pemahaman, keterampilan, dan sikap) dasar di bidang hospitaliti, khususnya dalam pengelolaan homestay. Berdasarkan penilaian peserta terhadap materi pelatihan yang diberikan sebagian besar peserta menilai materi sangat relevan dengan kebutuhan mereka. Semua peserta menyatakan setelah mengikuti pelatihan merasa mendapatkan tambahan pengetahuan, wawasan, dan keterampilan dalam operasional homestay. Kegiatan pelatihan dinyatakan sangat positif, penyajian dari narasumber yang baik sehingga mudah untuk dipahami dan diimplementasikan. Peserta juga berpendapat bahwa pelatihan menjadi penting untuk dilaksanakan di masa yang akan datang untuk peningkatan kompetensi dalam mengelola operasional Homestay di Desa Taro.

\section{PERNYATAAN PENGHARGAAN}

Program Studi Bisnis Horpitaliti melaksanakan kegiatan Pengabdian kepada Masyarakat, dengan lokus kegiatan di Desa Taro, Gianyar. Kegiatan ini berupa pendampingan (pelatihan), dengan tema "Pengelolaan Operasional Homestay di Desa Taro, Kecamatan Tegallalang, Kabupaten Gianyar-Bali” Kegiatan Pengabdian kepada Masyarakat ini berjalan dengan sangat baik karena bantuan dan dukungan berbagai pihak yang telah memberi kesempatan untuk membagi pengalaman dan ilmu kepada masayarakat. Pada kesempatan ini diucapkan penghargaan yang setinggi-tingginya kepada pimpinan Poltekpar Bali, Kepala Desa 
Taro, Ketua Pokdarwis Desa wisata Taro, serta pihak lain yang tidak dapat disebutkan satu persatu yang telah mendukung kegiatan pengabdian kepada masyarakat baik secara material maupun secara administrasi, sehingga kegiatan ini dapat terselesaikan dengan baik.

\section{DAFTAR PUSTAKA}

ASEAN Homestay Standard. (2016). Jakarta: ASEAN Secretariat.

Deputi Bidang Pengembangan Industri dan Kelembagaan Kementerian Pariwisata Republik Indonesia. (2019). Pengembangan Wisata Perdesaan \& Wisata Perkotaan: Rancangan Pola Perjalanan Gelang Projo (Magelang, Kulon Progo, Purworejo), Belitung Timur, Malang Raya. Jakarta.

Dessler, Gerry. (2005). Human Resource Management (Manajemen Sumber Daya Manusia). Edisi Kesembilan Jilid 2. Edisi Bahasa Indonesia. Jakarta: Indeks

Hadiwijoyo, Surya Sakti. (2012). Perencanaan Pariwisata Perdesaan Berbasis Masyarakat (Sebuah Pendekatan Konsep). Yogyakarta: Graha Ilmu.

Hasil APlikasi Bisnis Hospitaliti. (2021). Identifikasi Potensi Homestay di Desa Wisata Taro Tegalalang Gianyar Bali.

Panduan Pelaksanaan Kebersihan, Kesehatan, Keselamatan dan Kelestarian Lingkungan Homestay/Pondok Wisata. (2020). Kementerian Pariwisata dan Ekonomi Kreatif/Badan Pariwisata dan Ekonomi Kreatif Republik Indonesia

Sugiyono. (2013). Metode Penelitian Kuantitatif, Kualitatif, dan R\&D. Bandung: Alfabeta. 